\title{
EVALUATION OF CERTAIN PROBLEMS THAT MAY ARISE WITH SMART CONTRACTS FROM A LEGAL PERSPECTIVE
}

\author{
DOI: 10.17261/Pressacademia.2021.1479 \\ PAP- V.14-2021(5)-p.20-22
}

Ebru Sensoz Malkoc ${ }^{1}$, Zehra Badak², Selvi Nazli Guvenc ${ }^{3}$

${ }^{1}$ Istanbul Commerce University, Law Faculty, Istanbul, Turkey. esensoz@ticaret.edu.tr, ORCID: 000-0001-5542-1564

${ }^{2}$ Istanbul Commerce University, Law Faculty, Istanbul, Turkey. zbadak@ticaret.edu.tr, ORCID: 0000-0002-6793-8154

${ }^{3}$ Istanbul Commerce University, Law Faculty, Istanbul, Turkey. sguvenc@ticaret.edu.tr, ORCID: 0000-0002-3730-3860

\section{To cite this document}

Sensoz Malkoc, E., Badak, Z., Guvenc, S. N. (2021). Evaluation of certain problems that may arise with smart contracts from a legal perspective. PressAcademia Procedia (PAP), 14, 20-22.

Permanent link to this document: $\underline{\text { http://doi.org/10.17261/Pressacademia.2021.1479 }}$

Copyright: Published by PressAcademia and limited licensed re-use rights only.

\begin{abstract}
Purpose- The smart contract and blockchain concepts are being discussed in various disciplines as well as law with a rapid increase. However, in legal sense, the application of such concepts are far more advanced than the legal regulations on those topics not to mention the academic studies. Although there are a few distinguished monographies and a number of papers focusing the legal aspect, the applicability especially in certain circumstance - in which contractual law studies or defines as fundamental elements - are still vague. Therefore, this paper distinguishes itself by focusing on the purpose of studying some of the possible legal effects and results of smart contracts in commercial life as well as in finance.

Methodology- The study employs academic and theoretical analysis of the smart contracts concept from the point of legal theory, by making a thorough examination of diverse national and international papers, monographies and other studies.

Findings- As a result of this study it is revealed that smart contracts are already useful "tools" for commercial transactions especially for synallagmatic contracts with long terms, in finance and insurance sectors. Secondly, these types of contracts are going to be used more often in a broader sense. Thirdly, besides their advantages, such tools should be considered as a "contract" in legal sense, whether they are on-chain or off-chain or hybrid. Finally, since these are contracts, not a plain software, they are subject to the rules, theories, discussions and conditions of the relevant legal systems, specifically law of obligation. Therefore they should be subject to various legal regulations such as the provisions of standardized terms of contract, unfair terms and conditions, consumer law principles, finance law, insurance law, business law as well as banking law whenever applicable. Thus, the so called advantages of blockchain system, such as unanimity, decentralization, transparency and automation will be considered to be inapplicable from a legal perspective. In addition, if such contract contains a foreign element, the applicable local law should be determined according to the conflict of laws principles. Sometimes more than one local may be applicable to one single contract.

Conclusion- As a result of this study it is concluded that smart contracts are already a practical part of commercial transactions in especially finance and insurance sectors, and are going to be used more often within further commercial areas. However it is also observed that smart contracts will have shortcomings on some of its pormises such as confidentiality, reliability and sustainability. In addition, smart contract concept should be considered as a legal contract therefore it will always be under the scope of relevant legal regulations.
\end{abstract}

Keywords: Smart contracts, legal characteristics of smart contracts, blockchain, smart contracts and finance JEL Codes: K120, K20, K220

\section{INTRODUCTION}

Smart contracts become a very popular subject as a new way to execute agreements not only in technological sense but also in legal sense. Smart contracts can be broadly defined as "utilized protocols and user interfaces to facilitate all steps of the contracting process.contract" (Szabo, 1997). In other words; smart conracts are basicly transferring contractual terms into the software to execute and enforce them without any intermediary intervention by the trusted parties (Tevetoğlu, 2021). Therefore a smart contract is considered to be a set of promises, specified in digital form, including protocols within which the parties perform on these promises. 
Although smart contract concept may seem to be a newer technology, it is understood that it was introduced to the terminology in the 90s (Szabo, 1997; Badak, 2020; Tevetoğlu, 2021). However with the development of blockchain and distributed ledgers technology, the concept become more applicable. In other words, "Smart contracts exerting the blockchain technology can allow for a system of digital and open transactions between network users within a decentralized database (Philippe, 2018) with a more effective way.

This study focuses on this application of the smart contracts as a way to execute a contract, and tries to shed some light to the concept from a legal perspective.

\section{LITERATURE REVIEW}

In order to define the smart contract concept, the literature focuses on primarily to its automated structure. Kun points out that smart contracts are constructed as an autonomous execution of a piece of code "whose input or output can include money" (Kun 2021).

It is observed that some of the scholars agree that the smart contracts can be designed without blockchain technologies. In other words, blockchain is not a requirement for the implementation of these contracts because other technologies can maintain automatic execution (Kun, 2021). However there are also various opposition to this view which limits the definition within the blockchain. Those who discuesses smart contracts only with blockchain also defines smart contract as a piece of code which is stored on a Blockchain, triggered by Blockchain transactions, and which reads and writes data in that Blockchain's database." Thus, defining smart contracts as a transactional layer on top of blockchain would be an appropriate construction of the relationship between blockchains with smart contracts for these scholars.

Another important point to underline which is discussed in the literature is that smart contracts are not considered to be truly contracts in a legal sense, on the other hand a way of making agreement on online platforms, or codes ensuring the automated execution of the contract (Kun 142). However some scholars also defines such contracts as algorithms which would be legally enforceable (Scholz, 2017).

The scholars that accepts smart contracts can be executed without blockchain, offered three different types of the smart contracts; on-chain, off-chain and hybrid smart contracts (Sillaber and Waltl, 2017; Çağlayan Aksoy, 2021).

According to an opinion in the doctrine, the fact that the parties do not understand the content of the contract is no different from the possibility that the parties have not read the contract. Therefore, the contracting party who does not understand the programming language should be equated with the person who signed the contract without reading it (Çağlayan Aksoy, 2021). This brings us the question regarding the standardized terms of contract.

As can be understood from the definitions, smart contracts are not a document written on paper and signed, but a code stored and transacted on the blockchain. For this reason, smart contracts should be prepared in the form of "if/then" which is suitable for computer language. As a rule, a smart contract prepared in this way can automatically perform the performance when the conditions are met, without the need for the intervention of the parties or a third party (Kun, 2021). In some cases, the confirmation of whether the conditions specified in the smart contract are met may need an input from the outside world, since it cannot interact directly with the outside world, and these inputs can be provided by intermediaries called "oracle" (Kel, 2020; Badak, 2020; Tevetoğlu, 2021). Three types of oracles are mentioned, namely automated, trusted third party, andexpert oracles. Trusted third party and expert oracles can incorporate human views into smart contracts. Thus having a trusted oracle may soften the limitations of smart contracts, by using external data to trigger specific conditions in smart contracts. (de Flippi and Wright 2018; Çağlayan Aksoy, 2021).

The literature also points out that, although smart contracts and blockchain will bring a lot of advantages for especially financial transactions, there is also an undeniable the danger that if it is left uncontrolled, blockchains may create more unstable and unregulatable financial conditions and areas (de Flippi and Wright 2018; Karahan and Tüfekçi, 2019). In addition, the immutability, which seems to be an advantage in terms of smart contracts, are critisized for it necessity to search for different and vast amount of prefabricated legal solutions in each case (Karahan and Tüfekçi, 2019; Tevetoğlu, 2021).

\section{DATA AND METHODOLOGY}

The study adopted an analythical method to understand the applicable ways and foresee possible effects of a smart contract in various fields including the standardized terms of contract, comparative law, consumer law principles.

\section{FINDINGS}

Blockchain is a technology that blends different technologies such as peer to peer networks and cryptography and forms a new type of database, which is called as distributed ledger. Although blockchain is not the only example of a distributed ledger, it is the most wellknown example, followed by etherium. Smart contracts differ from traditional ones by their automatic enforcement as provided by their software protocols. This automatic performance is the consequence of embedding the required performance into the code. In other words specific performance is automated and guaranteed without any human intervention.

In order for a so called "smart contract" to form a "contract" within the framework of contract law, the necessary conditions for the establishment of the contract must be fulfilled within the framework of the existing rules of national law to be applied to the smart contract. Furthermore, it is obvious that blockchain enhances self-execution; however, it should be accepted that without using blockchain technology, automatic execution of a contractual duty, transferred into the codes, is still possible.

In the light of the aforementioned studies, it is observed that smart contracts have various advantages. Unanimity, transparency, automation, decentralization, immutability, removal of intermediaries, creating confidentiality, reduced transactional costs as there is no litigation or 
enforcement procedures in the case of a breach as the code ensures the performance of the contract, as well as taking computer code as a universal language and making it easier to reach a common understanding are all can be counted as advantages. Therefore smart contracts can be counted as useful "tools" for commercial transactions especially for synallagmatic contracts with long terms, in finance and insurance sectors.

However, unanimity and decentralization may also mean a disadvantage for especially consumers, when they need to reach a liable party in case of an occurance that is not regulated under the smart contract. This also means the removal of intermediaries may not always be an advantage as well. In addition to those, immutability is also pointed out as a disadvantage since it will result with unforeseen outcomes. Besides those point, the mining activities can be questioned for their electric consummation and impact on the environmental level. Cybersecurity and privacy (for the open systems) will also represent various disadvantages for the system as well. Another important point to take into account is the volatility of the cryptocurrencies that will be used in the smart contracts.

The fact that smart contracts are immutable programs due to the "immutable" nature of the blockchain, does not mean that the legal relationship between contractual parties is immutable and absolute. Although this limits the advantage of smart contracts in terms of intermediary involvement, it creates an assurance for the contracting parties. At this point, the important thing is that the smart contract code can adapt to this change in the legal situation, can be stopped when necessary and the performances can be returned. At this point, it may be possible to apply to a number of legal solutions that are valid for standard contracts and oracles.

However, in any case, the fact that the phenomenon, which is firstly described as a smart contract, can be defined as a contract within the framework of the law of obligations is a prerequisite, as is the case with traditional contracts. For instance, a smart contract, as any contract, will be subject to the regulations of standardized terms of contract, consumer protection laws, mandatory regulations of banking and finance industry. And those applicable rules will be decided according to the rules of conflict of laws.

\section{CONCLUSION}

As an emerging instrument, smart contracts could be useful tools financing and documentation processes in international trade, or research and development processes. Especially its efficiency regarding payment systems is undeniable. However, when there is a "contract» in legal sense, being subject to the legal control is inevitable. Furthermore, despite the convenience it provides; it is far from realizing a revolutionary change due to the risks it carries in terms of confidentiality, the inability to eliminate the need for an intermediary and the deficiencies in legal regulation. We believe that smart contracts will contribute to the continuation of the existing processes and parties in a more reliable and faster way, instead of changing the existing processes and parties in a revolutionary way. On the other hand, since smart contracts are processed on the blockchain in a way that cannot be changed, a necessity for competent and experienced intermediaries in this field will occur. Therefore, instead of elimintaing the intermediaries, existing intermediaries will change form and new concepts will be introduced to the system.

\section{REFERENCES}

Badak, Z. (2020). What will be the effect of distributed ledger technology law (dlt law, lex cryptographia) to the company law? A study on the future of the organization of companies with the new normal. Koronavirus Döneminde Güncel Hukuki Meseleler Sempozyumu, Ibn Haldun Üniversitesi.

Szabo, N. (1997). Formalizing and securing relationships on public networks, https://nakamotoinstitute.org/formalizingsecuringrelationships/ (last visited 30.11.2021)

Çağlayan Aksoy, P. (2020). Akıllı Sözleşmelerin Kuruluşu ve Geçerlilik Şartları.

de Filippi, P. and Wright, A. (2018). Blockchain and the Law 'The Rule of Code', Harvard University Press.

Karahan, Ç. and Tüfekci, A. (2019). Blokzincir teknolojisinin iç denetim faaliyetlerine etkileri: fırsatlar ve tehditler. Denetişim Dergisi, 9(19), 55-72.

Kun, E. (2021). Is Insisting on specific performance under smart contracts desirable under english law? Inflexibilities of smart contracts and potential solutions. Bilişim Hukuku Dergisi, 3(1), 139-175.

Philippe, D. (2018). Blockchain and smart contract: lex cryptographia? Article to be published in the legal review DAOR, https://philippelaw.eu/wp-content/uploads/2018/12/BLOCKCHAIN-AND-SMART-CONTRACT.pdf (last visited 30.11.2021)

Scholz, L. H. (2017). Algorithmic contracts. Stanford Technology Law Reviews, 20, 128-169.

Sillaber, C. and Waltl, B. (2017). Life cycle of smart contracts in blockchain ecosystems. Datenschutz und Datensicherheit 8 | 2017, p. 497500 .

Tevetoğlu, M. (2021). Ethereum ve akıllı sözleşmeler. InÜHFD, 12(1), 193-208. 